\title{
早寒武世初期化石尾海鞘的尾部具有 脊椎动物远祖的标志
}

\author{
张 爱 云 \\ (武汉地质学院北京研究生部)
}

十九世纪俄国科学家 A. O. 柯瓦利夫斯基研究了被襄动物海鞘的胚胎发育, 发现海鞘的 蝌蚪幼虫有一条独特的尾. 尾的中央有一条起支撑作用的硬的笔状体，不分节. 沿着尾的背 侧有一条神经管通过, 为中枢神经部分. 这一发现在科学界引起了骚动,因为它暗示了被亯动 物的幼虫必定与脊椎动物有密切的联系。从鱼到人的发展过程中, 各种脊椎动物在其自身发 育过程中, 都以简略的方式重演其祖先的发展历史. 脊索, 在脊索动物中唯有尾海鞘终身保 存, 其它的则见于发育早期, 成体后被脊椎代替. 显然, 脊索的出现为脊椎的形成铺平了道路. 因此, 研究化石尾海鞘的尾部具有重要的生物演化的意义.

\section{一、化石尾海鞘尾部构造的鉴别}

化石尾海鞘的(标本)尾部细长、实心，中央有一条硬的竿状体 (矿化)顺长度方向延伸 (图 1), 向上延伸到尾体联结处,未伸入到躯体内; 向下直达尾之末端. 脊索形状与尾部的形貌一 致,上宽下窄,末端呈尖或圆形,不分叉.其形状和所在位置与现代被震动物尾海鞘的脊索 ${ }^{[1-7]}$ 相当. 化石尾海鞘的脊索与现代的一样起着支撑尾部,使其保持一定形状和韧性的作用.
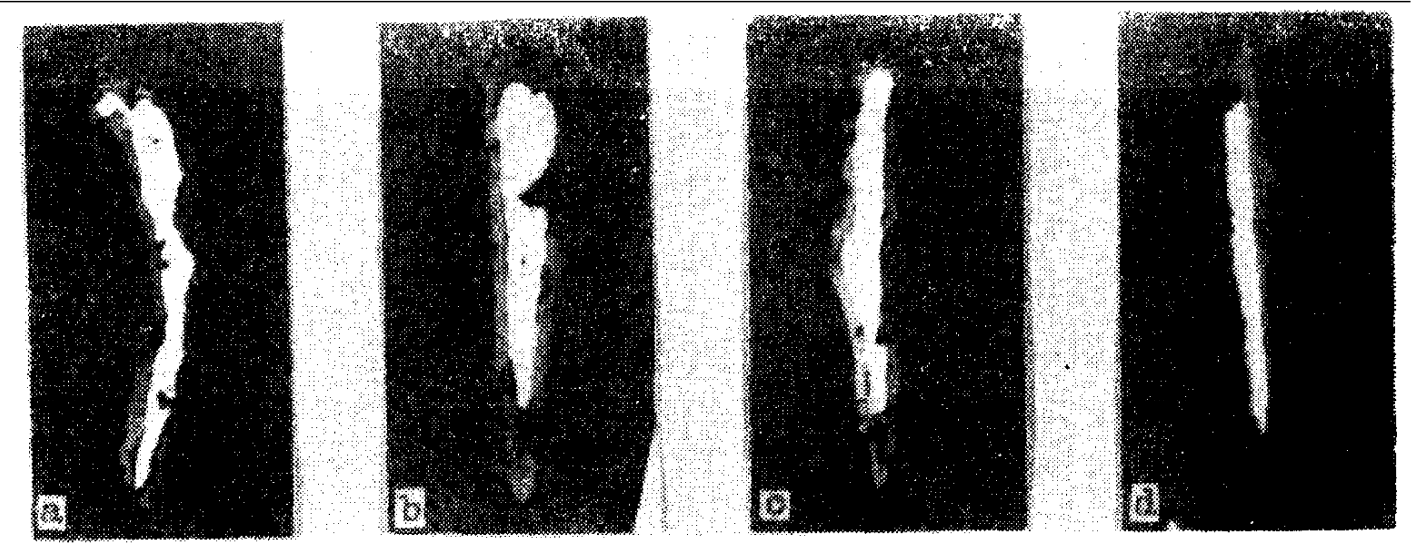

图 1 化石尾海鞘尾部的形态

a. $100 \times$; b. $320 \times$; c. $1137 \times$; d. $778 \times$

紧挨着化石尾海鞘脊索的边侧,其石化之肌肉, 保存良好. 细而长的肌细胞, 即肌纤维, 分 节成束分布 (图 2). 约可分为 8-10 节. 每节长度似乎不等. 这种纵肌纤维构成了尾部的体 壁肌肉. 现代被亯动物尾海鞘尾部的两侧也正是由分节的体壁肌肉组成的,它具有摆动的功 能 ${ }^{[2-\pi}$.化石尾海鞘中有的种在尾之后半部肌纤维上有数个或一排亚脊索细胞 (图 $1 \mathrm{~d}$, 左侧).

本文 1985 年 5 月 22 日收到。

第 12 期

科学 通报 
此类细胞之有无, 数目、形状及大小是现代尾海鞘分类的依据之一. 体壁肌肉的外面有表皮包 围, 表皮不易保存, 但也有局部隐现。
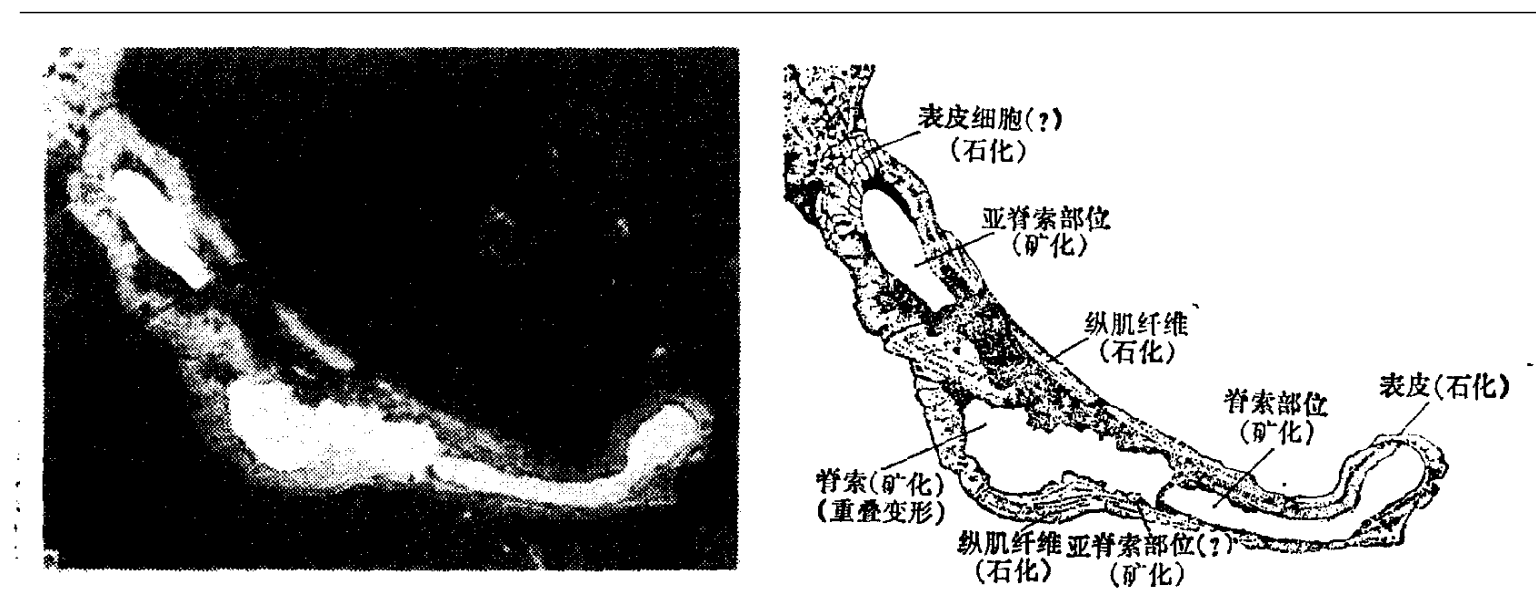

图 2 化石尾海鞘的尾部构造

a. 实体 $(\times 1266)$; b. 索描

化石尾海鞘的尾连于躯千腹面近中部 ${ }^{[8]}$, 尾的基部收缩. 其联结部位有一组细小、长卵形 的细胞, 是属表皮细胞还是肌细胞有待查证. 该组细胞分成三节呈栉状规则排列. 各节细胞 形态相似, 但数目不同. 最上一节细胞呈栉状直排,其数量比下面第二、三节减少将近 $1 / 2$.下 面两节细胞呈栉状排成弧形，向下延伸。尾体联结处这种分节成层、上下成套的细胞排列形 式,正是与其尾部具有转动功能的特性相适应的.

\section{二、结 论}

对早寒武世初期化石尾海鞘尾部的剖析表明,一条脊索支撑着肌性的尾部,是脊椎动物远 祖类型的标志. 为无脊椎动物通过中间类型一原索动物向脊椎动物演化, 从化石记录上得 到了证实.

致谢: 在本文撰写的过程中, 承南海水产研究所杨国峰副研究员王永平提出宝贵意见, 特此表示哀心的 感谢.

\section{参文献}

[1] Berrill, N. J., Tunicate with an account of the Btitish Species, The Ray Society, Instituted 1844, London, 1950, 133: 302-322.

[ 2 ] Berrill, N. J., The Encyclopedia American, International edition 6, 1980, 220-221.

[3] Alice Alldredge, Appendicularians, Scientific American, 235 (1976), 1: 95-102.

[ 4 ] Thomposon, H., Handbook of Australian, Pelagic Tunicates, 1948, 5-80.

[ 5 ] Clande, A. V., Warren, Jr. F. W., Fredrick, E. S., General Zoology, 1978, 206-225, 754-771.

[6] 武汉大学、南京大学、北京师范大学, 普通动物学, 人民教育出版社, 1984, 268-280.

[ 7 ] 郑重、李少蓄、许振祖, 海洋浮游生物学, 海洋出版社, 1984, 527-547.

[ 8 ] 张爱云, 寨武纪初期被震动物化石的发现, 科学通报, 30(1985). 5: 324-327. 